\title{
LỒNG GHÉP YÊU CẦU BẢO VỆ MÔI TRƯỜNG TRONG HÊ THỐNG PHÁP LUÂTT CHUYÊN NGÀNH Ở VIẸTT NAM - MỘT SỐ VẤN ĐỀ LÝ LUẬN
}

\author{
Mai Thanh Dung ${ }^{1}$, Nguyễn Minh Khoa ${ }^{1}$, Phan Thị Thu Hương ${ }^{1}$
}

Tóm tắt: Mối quan tâm ngày càng lớn về môi trương và muc tiêu phát triển bền vũng là các động lực thúc đẩy việc lồng ghép môi trương trong các chính sách phát triển, cüng nhu cu thể hóa trong việc lồng ghép yêu cầu bảo vệ môi trương vào hệ thống pháp luật chuyên ngành. Việc lồng ghép yêu cầu bảo vệ môi truờng có vai trò to lớn trong việc đảm bảo sụ thống nhất, hài hòa các quy định về bảo vệ môi truờng, khắc phục các chồng chéo, mâu thuẫn, thiếu hụt trong hệ thống pháp luật, qua đó nâng cao hiệu quả thực thi bảo vệ môi trương chung. Đây cũng là nhu cầu cấp thiết đặt ra đối với Việt Nam trong bối cảnh pháp luật hiện nay. Dựa trên kết quả phân tích các nghiên cứu trong và ngoài nước có liên quan để làm rõ sụ hình thành và phát triển lý luận về lồng ghép yêu cầu bảo vệ môi truờng, bài viết luận giải sụ cần thiết và xác định các định huớng về lồng ghép yêu cầu bảo vệ môi trương vào hệ thống pháp luật chuyên ngành ở Việt Nam.

Từ khóa: Lồng ghép yêu cầu bảo vệ môi trương, hệ thống pháp luật chuyên ngành, phát triển bền vĩng.

Ban Biên tập nhận bài: 12/08/2019 Ngày phản biện xong: 20/09/2019 Ngày đăng bài: 25/10/2019

\section{1. Đặt vấn đề}

Lồng ghép yêu cầu bảo vệ môi trường vào các quyết định sử dụng các nguồn lực trong hoạt động kinh tế, xã hội là cách thức bảo vệ môi trường có nguồn gốc từ yêu cầu phát triển bền vững, nguyên tắc phòng ngừa trong bảo vệ môi trường và nguyên tắc đảm bảo sự tham gia của cộng đồng vào các quyết định có liên quan tới môi trường. Yêu cầu phát triển bền vững đến nay được coi là một trong những giá trị phổ quát cần được đảm bảo bởi bất kỳ mô hình phát triển kinh tế nào trên thế giới. Phát triển bền vững được Ủy ban thế giới về Môi trường và phát triển (WCED-1987) [1] định nghĩa là "sự phát triển nhằm đáp ứng những nhu cầu của hiện tại, nhưng không gây trở ngại cho việc đáp ứng nhu cầu của các thế hệ mai sau". Yêu cầu phát triển bền vững được hiểu một cách giản lược là yêu cầu phát triển kinh tế phải đi đôi với việc bảo vệ thỏa đáng môi trường sinh thái. Điều này cũng có nghĩa

${ }^{1}$ Viện Chiến lược, Chính sách tài nguyên và môi trường

Email:mtdung@isponre.gov.vn rằng, mọi hoạt động kinh tế, xã hội đều phải tính đúng, tính đủ các chi phí cho việc bảo vệ môi trường. Lồng ghép yêu cầu bảo vệ môi trường chính là quá trình lồng ghép hay tích hợp các mục tiêu môi trường vào trong các ngành luật không phải về môi trường (chẳng hạn như năng lượng, nông nghiệp, xây dựng, giao thông...), dựa trên nhận thức cơ bản rằng giải quyết các vấn đề về môi trường không thể chỉ dựa vào mỗi pháp luật môi trường. Chính vì vậy, lồng ghép yêu cầu bảo vệ môi trường được coi là một công cụ có vai trò rất quan trọng với phát triển bền vững.

Dù phát triển trên thế giới từ lâu song tại Việt Nam, việc nghiên cứu về lồng ghép môi trường vào hệ thống pháp luật chuyên ngành vẫn là một lĩnh vực khá mới mẻ, số nghiên cứu liên quan tới chủ đề này còn khá ít ỏi. Nghiên cứu này sẽ góp phần cung cấp khái quát cơ sở lý luận về lồng ghép môi trường và làm rõ sự cần thiết, cũng như xác định một số định hướng đối với việc lồng ghép yêu cầu bảo vệ môi trường vào hệ thống pháp luật chuyên ngành ở Việt Nam. 


\section{Phương pháp nghiên cứu}

Thông tin, dữ liệu thứ cấp được sử dụng trong nghiên cứu này bao gồm các nguồn tư liệu đã được công bố chính thức của các tác giả trong và ngoài nước về vấn đề lồng ghép môi trường trong chính sách phát triển và lông ghép yêu cầu bảo vệ môi trường trong hệ thống pháp luật chuyên ngành, cũng như các nghiên cứu có liên quan. Dữ liệu sơ cấp được sử dụng là các nguồn thông tin được thu thập thông qua phỏng vấn, tham vấn ý kiến của các cơ quan nghiên cứu của mỗi bộ, ngành, các trường đại học, các chuyên gia để có được các thông tin bổ sung, tư liệu liên quan đến chủ đề nghiên cứu.

Phương pháp nghiên cứu sử dụng bao gồm phương pháp phân tích chính sách, phương pháp chuyên gia, phương pháp phân tích logic hệ thống, phương pháp kế thừa và chọn lọc trong việc tận dụng các thành quả của các nhà khoa học đi trước, sử dụng các kết quả nghiên cứu của các đề tài, dự án thuộc các Chương trình khoa học và công nghệ có liên quan.

\section{Kết quả và thảo luận}

3.1. Quá trình hình thành lồng ghép môi trường trong chính sách phát triển và lồng ghép yêu cầu bảo vệ môi trừ̀ng trong hệ thống pháp luật chuyên ngành

Nhận thức và tư duy của các nước trên thế giới về phát triển và bảo vệ tài nguyên, môi trường đã có những thay đổi theo hướng ngày càng coi trọng hơn công tác bảo vệ môi trường. Từ chỗ "chỉ phát triển, không chú trọng đến bảo vệ môi trường” vào những năm trước 1950, đến "phát triển trước, bảo vệ môi trường sau" (giai đoạn 1950 - 1990), đến "lồng ghép bảo vệ môi trường để phát triển bền vững" (giai đoạn 1990 - 2010) và từ 2012 là "khuyến khích đầu tư cho bảo vệ môi trường để tăng trưởng kinh tế, phát triển nền kinh tế xanh". Cùng với sự thay đổi đó, các nghiên cứu và triển khai áp dụng liên quan đến lồng ghép/tích hợp môi trường ngày một phổ biến hơn. Vấn đề và các yêu cầu về lồng ghép chính sách môi trường (Environmental Policy Integration - EPI) cũng đã nằm trong các chương trình nghị sự trong nhiều thập kỷ và dần được quan tâm mạnh mẽ tại các diễn đàn quốc tế những năm gần đây. Sự quan tâm tới EPI đang chuyển hướng cả trong thực tiễn lẫn trong nghiên cứu. Ở cấp độ quốc tế, đã có một sự quan tâm mới, cả trước và sau Rio+20 vào năm 2012, trong nhiệm vụ rộng hơn và chung hơn cho hội nhập của môi trường, chính sách kinh tế và xã hội. Ở cấp quốc gia, thay vào đó, tập trung vào các hình thức hội nhập cụ thể hơn. Ở đây, không chỉ CPI (tích hợp chính sách khí hậu) được quan tâm; các hình thức khác của EPI theo ngành, chẳng hạn như tích hợp đa dạng sinh học cũng đang nổi lên. Cuối cùng, mặc dù các nỗ lực EPI ở cấp quốc gia và địa phương đã được ghi nhận và được đánh giá, cần nhiều công việc hơn để phát triển một nền tảng tri thức về đẩy mạnh tích hợp môi trường ở cấp độ quốc tế, nơi mà nhiều các vấn đề môi trường phát sinh, và những thách thức và rào cản thể chế đối với EPI được nhấn mạnh [2].

Lafferty và Hovden (2003) [3] dựa trên các nghiên cứu của Underdal (1980) [4] và Peters (1998) [5] về tích hợp chính sách (policy integration) đã phát triển khái niệm tích hợp chính sách môi trường (EPI) và cho rằng vấn đề quan trọng trong đánh giá EPI là trọng số tương đối cho các mục tiêu của các ngành và môi trường trong hoạch định chính sách. Nguyên tắc và thực tiễn của EPI nhằm mục đích giúp đỡ việc hài hoà các mục tiêu kinh tế và môi trường bằng cách chủ động tìm kiếm cơ hội sớm trong quá trình hoạch định chính sách của bất kỳ ngành nào, ưu tiên vấn đề môi trường. EPI được thúc đẩy bởi sự công nhận rằng mỗi ngành tự nó sẽ không thể thực hiện được các mục tiêu môi trường của chúng ta. Thay vào đó mỗi ngành phải tính đến các mục tiêu chính sách về môi trường nếu những điều này là có thể đạt được.

Có thể thấy lồng ghép yêu cầu bảo vệ môi trường vào các quyết định sử dụng các nguồn lực trong hoạt động kinh tế, xã hội là cách thức bảo vệ môi trường có nguồn gốc từ yêu cầu phát triển bền vững [6], nguyên tắc phòng ngừa trong bảo vệ môi trường và nguyên tắc đảm bảo sự tham gia của cộng đồng vào các quyết định có liên 
quan tới môi trường.

Yêu cầu phát triển bền vững được hiểu một cách giản lược là yêu cầu phát triển kinh tế phải đi đôi với việc bảo vệ thỏa đáng môi trường sinh thái. Nguyên tắc phòng ngừa đòi hỏi giảm thiểu tối đa nguy cơ sản sinh ra tác nhân làm thiệt hại đến môi trường (gây ô nhiễm, suy thoái môi trường) thay cho việc xử lý các chất gây ô nhiễm đã được sản sinh từ quá trình sản xuất, sinh hoạt của con người. Nguyên tắc đảm bảo sự tham gia của cộng đồng vào quá trình ra các quyết định quan trọng liên quan tới môi trường đòi hỏi bất cứ khi nào một chủ thể có các quyết định có thể ảnh hưởng tiêu cực tới môi trường nơi một cộng đồng dân cư đang sinh sống thì đều phải có sự tham vấn ý kiến hợp lý của cộng đồng dân cư đó. Như vậy, lồng ghép yêu cầu bảo vệ môi trường vào các loại quyết định trong cuộc sống của con người phải được coi là một hệ quả tự nhiên của yêu cầu phát triển bền vững và đáp ứng nguyên tắc phòng ngừa trong việc bảo vệ môi trường và nguyên tắc đảm bảo sự tham gia của cộng đồng vào quá trình bảo vệ môi trường.

Tại Việt Nam, hiện nay, có nhiều định nghĩa khác nhau liên quan tới lồng ghép/tích hợp bảo vệ môi trường. Nội hàm của các khái niệm này cùng hướng đến một mục tiêu là xem xét vấn đề cần tích hợp vào quá trình thực hiện nhằm đạt được các hiệu quả mong muốn. Tuy nhiên, khái niệm tích hợp và lồng ghép thường bị coi là một và sử dụng tương tự nhau. Theo tác giả Tô Thúy Nga (2015) [7] thì lồng ghép là một khái niệm mang tính toàn diện, vĩ mô, xem xét vấn đề ở cấp chính sách nhằm điều chỉnh các hoạt động của tất cả các lĩnh vực trong xã hội thông qua việc dự báo các tác động tiềm tàng liên quan đến môi trường để xây dựng các chiến lược, chính sách phát triển quốc gia, ngành, địa phương. Tích hợp là quá trình thực hiện lồng ghép, nhằm đảm bảo việc thực hiện các mục tiêu của lồng ghép ở cấp độ chính sách và giải pháp cụ thể. Có thể hiểu lồng ghép môi trường trong chính sách phát triển gần với tích hợp môi trường theo ý nghĩa là quá trình đưa các mục tiêu về môi trường vào tất cả các bước của quá trình hoạch định chính sách của tất cả các ngành; xem xét các tác động đến các hoạt động BVMT trong khi tiến hành đánh giá và xây dựng chính sách tổng thể, do đó, sẽ làm giảm mâu thuẫn giữa các chính sách liên quan đến môi trường với các chính sách khác. Tích hợp môi trường được thực hiện trong các quá trình ra quyết định, lập kế hoạch và chương trình của một quốc gia, vùng hay lĩnh vực, ngành nghề nhằm hiểu rõ khả năng của tài nguyên, tác động thực sự của môi trường lên phát triển và cải thiện quá trình ra quyết định. Còn đối với lồng ghép môi trường trong hệ thống pháp luật chuyên ngành, đây là một hoạt động hay cách thức có mục tiêu trực tiếp hơn, đó là quy phạm pháp luật hóa các quy phạm về bảo vệ môi trường vào trong các luật, văn bản dưới luật của các pháp luật chuyên ngành có liên quan, tiêu biểu như pháp luật về quản lý tài nguyên, năng lượng, xây dựng, đầu tư...để nâng cao hiệu lực, hiệu quả pháp lý về bảo vệ môi trường trong từng chuyên ngành đó, qua đó góp phần nâng cao hiệu quả bảo vệ môi trường chung mà chỉ riêng pháp luật về môi trường thì không đủ.

Như vậy, có thể coi lồng ghép môi trường vào hệ thống pháp luật là quá trình đưa các yêu cầu bảo vệ môi trường thành các quy định cụ thể trong pháp luật chuyên ngành còn lồng ghép môi trường trong chính sách phát triển mang tính vĩ mô, đề ra các nguyên tắc, định hướng, nhiệm vụ chủ đạo quá trình triển khai thực hiện các chính sách lồng ghép cụ thể về bảo vệ môi trường trong thực tiễn.

Giữa lồng ghép môi trường trong chính sách phát triển và lồng ghép môi trường trong hệ thống pháp luật chuyên ngành có mối quan hệ rất gắn bó và chặt chẽ với nhau vì cùng hướng tới mục tiêu lồng ghép môi trường, cùng hướng tới việc phát triển bền vững. Lồng ghép môi trường trong hệ thống pháp luật chuyên ngành cần hướng theo các định hướng của lồng ghép môi trường trong chính sách phát triển và cụ thể hóa trong các văn bản pháp luật chuyên ngành có liên quan để khắc phục sự không thống nhất, mâu thuẫn, cùng phát huy được hiệu lực tổng hợp của hệ thống pháp luật đối với việc bảo vệ môi 
trường. Trong khi lồng ghép môi trường trong chính sách phát triển hướng tới đối tượng tác động xây dựng và hoạch định chính sách thì lồng ghép môi trường trong hệ thống pháp luật chuyên ngành sẽ cụ thể hóa bằng các quy định về môi trường trong các văn bản pháp luật chuyên ngành liên quan.

\subsection{Sự cần thiết của lồng ghép yêu cầu bảo vệ môi truờng vào hệ thống pháp luật chuyên ngành ở Việt Nam}

Đất nước ta đang trong thời kỳ đẩy mạnh công nghiệp hóa, hiện đại hóa, nguy cơ gia tăng ô nhiễm môi trường, suy thoái tài nguyên thiên nhiên đang và sẽ là các vấn đề chúng ta phải đối mặt trong quá trình này. Mặt khác, nhu cầu phát triển kinh tế, thu hút đầu tư, tạo điều kiện cho doanh nghiệp hoạt động đang đòi hỏi thông thoáng và tinh gọn các thủ tục hành chính, hạn chế tối đa các quy định mâu thuẫn, chồng chéo. Việc hoàn thiện thể chế, chính sách, pháp luật đã được Đảng, Nhà nước xác định là một trong ba đột phá chiến lược trong Chiến lược pháp triển kinh tế - xã hội của đất nước. Hệ thống pháp luật về môi trường trong thời gian qua đã được xây dựng và ngày càng được hoàn thiện để đáp ứng được yêu cầu, nhiệm vụ đặt ra đối với công tác quản lý nhà nước về bảo vệ môi trường (BVMT). Bên cạnh các quy định pháp luật bảo vệ môi trường do Bộ Tài nguyên và Môi trường chủ trì trình hoặc tự ban hành, các yêu cầu về bảo vệ môi trường còn được quy định ở nhiều luật khác nhau (như Luật Đầu tư, Luật Đầu tư công, Luật Xây dựng, Luật Tài nguyên nước, Luật Quy hoạch đô thị, Luật Khoa học và Công nghệ, Luật Đất đai v.v). Tuy nhiên, thực tế cho thấy tình trạng ô nhiễm, suy thoái môi trường vẫn diễn ra ở nhiều nơi.

Trong quá trình triển khai pháp luật môi trường đã bộc lộ một số tồn tại, hạn chế cần thiết phải sửa đổi, bổ sung để đảm bảo phù hợp với thực tế, tháo gỡ khó khăn cho bộ, ngành, địa phương và các đối tượng liên quan, cụ thể:

- Một số quy định trong pháp luật về bảo vệ môi trường còn chưa sát thực tế, thiếu cụ thể dẫn đến chậm đi vào cuộc sống, không theo kịp yêu cầu phát triển của thực tiễn và hội nhập quốc tế; còn những khoảng trống trong các quy định của pháp luật về bảo vệ môi trường... đã làm giảm hiệu lực và hiệu quả của công tác quản lý nước về bảo vệ môi trường.

- Cơ chế, chính sách bảo vệ môi trường chưa theo kịp, phù hợp và đồng bộ với thể chế kinh tế thị trường. Các loại thuế, phí về môi trường theo nguyên tắc "người gây ô nhiễm phải trả chi phí xử lý, khắc phục, cải tạo và phục hồi môi trường", "người hưởng lợi từ giá trị môi trường phải trả tiền" mới chỉ bước đầu tạo nguồn thu cho ngân sách mà chưa phát huy được vai trò công cụ kinh tế điều tiết vĩ mô, hạn chế các hoạt động gây ô nhiễm, suy thoái môi trường, thúc đẩy phát triển kinh tế - xã hội theo hướng tăng trưởng xanh.

- Phân công, phân cấp thẩm quyền trong quản lý môi trường vẫn còn chồng chéo và chưa hợp lý, chưa đi đôi với tăng cường năng lực, phân định rõ trách nhiệm. Việc phân công, phân cấp trách nhiệm, thẩm quyền trong việc giải quyết các vấn đề môi trường có tính liên vùng, liên ngành chưa được quy định cụ thể, rõ ràng dẫn đến sự phối hợp không nhất quán, còn lúng túng, hiệu quả chưa cao khi có vụ việc về ô nhiễm, sự cố môi trường xảy ra. Có thể thấy nguyên nhân chính dẫn đến tình trạng này là việc không tuân thủ các yêu cầu BVMT ở nhiều ngành, lĩnh vực sản xuất kinh doanh, nhận thức trách nhiệm về thực hiện các yêu cầu bảo vệ môi trường của các tổ chức, cá nhân, thậm chí của các cấp có thẩm quyền chưa đầy đủ.

Để cải thiện tình trạng này, các yêu cầu bảo vệ môi trường cần được quy định trong hệ thống pháp luật chuyên ngành là hết sức cần thiết. Tuy nhiên, qua rà soát ban đầu thấy rằng:

a) Yêu cầu bảo vệ môi trường của pháp luật bảo vệ môi trường hầu như chưa được đưa vào hệ thống pháp luật chuyên ngành. Ơ đây có cả nguyên nhân khách quan lẫn chủ quan:

- Nhiều văn bản quy phạm pháp luật chuyên ngành được ra đời trước khi có Luật BVMT 2014;

- Yêu cầu lồng ghép các quy định về bảo vệ 
môi trường không được đặt ra khi xây dựng các văn bản pháp luật chuyên ngành.

b) Các quy định bảo vệ môi trường được quy định ở nhiều luật khác nhau (như Luật Đầu tư, Luật Đầu tư công, Luật Xây dựng, Luật Tài nguyên nước, Luật Khoáng sản...), song giữa các luật này còn nhiều nội dung giao thoa, thiếu thống nhất, thậm chí là mâu thuẫn trong các quy định cụ thể, đã tác động tiêu cực, làm cho công tác quản lý nhà nước và thực thi pháp luật về bảo vệ môi trường gặp nhiều khó khăn, vướng mắc cho cả cơ quan quản lý nhà nước cũng như cho người dân và doanh nghiệp. Chẳng hạn, Luật Bảo vệ môi trường 2014 quy định "Quyết định phê duyệt báo cáo đánh giá tác động môi trường là căn cứ để cấp có thẩm quyền quyết định chủ trương đầu tư dự án", trong khi đó Luật Đầu tư năm 2014, Luật Đầu tư công năm 2014 không yêu cầu nhà đầu tư phải có trước thời điểm quyết định chủ trương đầu tư. Sự không thống nhất này gây nhiều khó khăn, lúng túng cho người dân, doanh nghiệp và cơ quan quản lý nhà nước trong việc áp dụng pháp luật, dẫn tới có nhiều trường hợp cơ quan có thẩm quyền vẫn quyết định đầu tư khi chưa có báo cáo ĐTM được phê duyệt.

Trong bối cảnh sức ép lên môi trường ngày càng gia tăng từ các hoạt động phát triển kinh tế - xã hội hiện nay, vai trò của lồng ghép yêu cầu bảo vệ môi trường vào hệ thống pháp luật chuyên ngành do đó ngày một quan trọng và cấp thiết.

3.3. Một số định hướng về lồng ghép yêu cầu bảo vệ môi truờng trong hệ thống pháp luật chuyên ngành

Mục tiêu quan trọng là hướng tới xác lập các nội dung cơ bản về yêu cầu bảo vệ môi trường quy định trong pháp luật BVMT cần đưa vào hệ thống pháp luật chuyên ngành. Việc lồng ghép yêu cầu BVMT trong hệ thống pháp luật chuyên ngành cần hướng tới việc khắc phục các thiếu hụt, bất cập về yêu cầu bảo vệ môi trường trong hệ thống pháp luật hiện nay, đảm bảo đồng bộ, thống nhất các yêu cầu bảo về môi trường trong hệ thống pháp luật Việt nam, nâng cao hiệu lực, hiệu quả thực thi pháp luật bảo vệ môi trường góp phần thực hiện mục tiêu phát triển bền vững.

Việc lồng ghép cần hướng tới thực hiện trên quan điểm phát triển bền vững và dựa trên cơ sở khoa học, pháp lý cơ bản sau đây:

+ Bảo vệ môi trường; quản lý, sử dụng hiệu quả, bền vững các nguồn tài nguyên thiên nhiên; bảo tồn thiên nhiên, đa dạng sinh học; chủ động phòng, chống thiên tai, ứng phó với biến đổi khí hậu (Điều 63 Hiến pháp). Tích cực thực hiện "Chương trình nghị sự 2030 vì sự phát triển bền vững" của Liên hợp quốc; triển khai chiến lược tăng trưởng xanh; kết hợp chặt chẽ phát triển kinh tế nhanh và bền vững với phát triển xã hội bền vững; hoàn thiện pháp luật để tăng cường hiệu lực, hiệu quả cơ chế giám sát, thanh tra, kiểm tra, xử lý vi phạm pháp luật về bảo vệ môi trường (Nghị quyết số 11-NQ/TW về hoàn thiện thể chế kinh tế thị trường định hướng xã hội chủ nghĩa của Ban Chấp hành Trung ương Đảng Cộng sản Việt Nam khóa XII, đã xác định một trong những nhiệm vụ đặt ra và giải pháp chủ yếu đến năm 2020).

+ Đổi mới, hoàn thiện cơ chế, chính sách tài chính, tăng cường và đa dạng hóa nguồn lực cho ứng phó với biến đổi khí hậu, quản lý tài nguyên và bảo vệ môi trường; Quán triệt và vận dụng có hiệu quả các nguyên tắc: người gây ô nhiễm phải trả chi phí để xử lý, khắc phục hậu quả, cải tạo và phục hồi môi trường; người được hưởng lợi từ tài nguyên, môi trường phải có nghĩa vụ đóng góp để đầu tư trở lại cho quản lý tài nguyên và bảo vệ môi trường (Nghị quyết số 24-NQ/TW ngày 3 tháng 6 năm 2013 Hội nghị Trung ương 7 khóa XI về chủ động ứng phó với biến đổi khí hậu, tăng cường quản lý tài nguyên và bảo vệ môi trường).

+ Khắc phục những vướng mắc của Luật Bảo vệ môi trường hiện hành và đảm bảo tính thống nhất của hệ thống pháp luật và tháo gỡ khó khăn cho doanh nghiệp: Một số quy định trong pháp luật về bảo vệ môi trường còn chưa sát thực tế, thiếu cụ thể dẫn đến chậm đi vào cuộc sống, không theo kịp yêu cầu phát triển của thực tiễn. Bên cạnh đó, các quy định bảo vệ môi trường được quy định ở nhiều luật khác nhau (như Luật 
Đầu tư, Luật Đầu tư công, Luật Xây dựng, Luật Tài nguyên nước, Luật Khoáng sản, dự thảo Luật Quy hoạch...), song giữa các luật này còn một số điểm còn có sự giao thoa, chưa thống nhất, còn một số khoảng trống chưa được quy định đã ảnh hưởng tới hiệu quả quản lý nhà nước về bảo vệ môi trường. Cơ chế, chính sách bảo vệ môi trường chưa theo kịp, phù hợp và đồng bộ với thể chế kinh tế thị trường. Các loại thuế, phí về môi trường theo nguyên tắc "người gây ô nhiễm phải trả chi phí xử lý, khắc phục, cải tạo và phục hồi môi trường", "người hưởng lợi từ giá trị môi trường phải trả tiền" mới chỉ bước đầu tạo nguồn thu cho ngân sách mà chưa phát huy được vai trò công cụ kinh tế điều tiết vĩ mô, hạn chế các hoạt động gây ô nhiễm, suy thoái môi trường, thúc đẩy phát triển kinh tế - xã hội theo hướng tăng trưởng xanh. Chưa tạo ra hành lang pháp lý và môi trường thuận lợi để khuyến khích phát triển dịch vụ môi trường, sản phẩm thân thiện với môi trường, khuyến khích xã hội hóa trong một số hoạt động bảo vệ môi trường.

+ Đảm bảo thực thi các điều ước quốc tế, trong đó đặc biệt là Thỏa thuận Paris được thông qua tại Hội nghị các bên lần thứ 21 của Công ước khung Liên Hợp quốc về biến đổi khí hậu (COP 21). Với vai trò của một nước thành viên, Việt Nam cam kết đến năm 2030, sẽ cắt giảm $8 \%$ phát thải khí nhà kính so với kịch bản phát triển thông thường, với mục tiêu cắt giảm đến $25 \%$ nếu nhận được hỗ trợ của cộng đồng quốc tế. Điều đó đặt ra những yêu cầu về bổ sung và điều chỉnh các quy định về ứng phó với biến đổi khí hậu ở Việt Nam. Đến năm 2015, 17 Mục tiêu về phát triển bền vững (SDGs) của Liên hiệp quốc chính thức được sử dụng thay thế cho các Mục tiêu phát triển thiên niên kỷ. Nhiều mục tiêu SDGs về môi trường là những thách thức khá lớn đối với nước ta, một phần bởi hệ thống chính sách, pháp luật của Việt Nam chưa hoàn thiện để triển khai, giám sát và khuyến khích các hoạt động bảo vệ môi trường nhằm đạt được các mục tiêu SDGs. Ngoài ra, việc đàm phán nội dung liên quan đến bảo vệ môi trường trong các thỏa thuận và hiệp định thương mại quốc tế như các Hiệp định thương mại tự do (FTAs), Hiệp định đối tác toàn diện và tiến bộ xuyên Thái Bình Dương (CPTPP) đã và đang dần trở thành một xu hướng trên thế giới. Vì vậy, cần rà soát và xem xét điều chỉnh các quy định trong nước để hài hòa và tạo cơ sở pháp lý cho việc đàm phán và triển khai các hiệp định thương mại trong tương lai.

\section{Kết luận}

Từ lý luận tới thực tiễn, lồng ghép môi trường trong chính sách phát triển và lồng ghép yêu cầu bảo vệ môi trường đã trải qua nhiều thập kỷ phát triển trên thế giới. Tuy nhiên, đây vẫn là một lĩnh vực còn tương đối mới mẻ ở Việt Nam và còn chưa có nhiều nghiên cứu về vấn đề này. Bài viết đã góp phần cũng cấp một số cơ sở lý luận cũng như làm sáng tỏ mối quan hệ giữa lồng ghép môi trường trong chính sách phát triển và lồng ghép yêu cầu bảo vệ môi trường vào hệ thống pháp luật chuyên ngành.

Có thể thấy, với bối cảnh Việt Nam hiện nay, lồng ghép yêu cầu bảo vệ môi trường vào trong hệ thống pháp luật chuyên ngành có vai trò và ý nghĩa rất to lớn. Hệ thống pháp luật chuyên ngành hiện tại vẫn đang mang nặng tư duy phát triển cục bộ, gắn với lợi ích ngành mà chưa xem xét thỏa đáng tới yêu cầu bảo vệ môi trường vì lợi ích phát triển chung. Điều này dẫn tới hiện trạng hệ thống pháp luật của các ngành bỏ qua hoặc quy định rất sơ sài về nội dung bảo vệ môi trường, thậm chí bỏ qua yêu cầu về môi trường với lĩnh vực quản lý của ngành. Điều này đã để lại nhiều hệ quả tiêu cực, làm giảm hiệu lực pháp luật, gây khó khăn cho doanh nghiệp và người dân. Mặt khác, trong bản thân hệ thống pháp luật bảo vệ môi trường cũng đang tồn tại nhiều hạn chế, bất cấp, chồng chéo với các lĩnh vực khác, gây khó khăn với cả các cấp quản lý. Đảng và Nhà nước trong thời gian qua cũng đã nhìn nhận, đánh giá đúng về vấn đề này và đã ban hành nhiều văn bản nêu cao vai trò và đề ra các định hướng cho việc lồng ghép. Bởi vậy, vấn đề lồng ghép yêu cầu bảo vệ môi trường vào trong hệ thống pháp luật chuyên ngành là rất cần thiết trong bối cảnh hiện nay. 


\section{BÀI BÁO KHOA HỌC}

Lời cảm ơn: Nghiên cưu này là kết quả của đề tài "Nghiên cứu lồng ghép yêu cầu bảo vệ môi trường trong hệ thống pháp luật chuyên ngành”, Mã số BĐKH.37/16-20 thuộc Chuơng trình Khoa họ và công nghệ ưng phó với biến đổi khí hậu, quản lý tài nguyên và môi truòng giai đoạn 2016-2020.

\section{Tài liệu tham khảo}

1. WCED (1987), Report of the world commission on environment and development: our common future, Oxford University Press.

2. Adelle, C., Nilsson, M., (2015), Environmental Policy Integration. Encyclopedia of Global Environmental Politics and Governance.

3. Lafferty, W.M., Hovden, E., (2003), Environmental Policy Integration: Towards an Analytical Framework. Environmental politics, 12 (3), 1-22.

4. Underdal, A., (1980), Integrated marine policy: what? why? how? Marine Policy, 4 (3), 159169.

5. Persson, A., (2004), Environmental Policy Integration: An Introduction. Stockholm Environment Institute.

6. Trần Chí Trung, Lê Trọng Cúc, Nguyễn Mạnh Hà (2010), Thách thức lồng ghép môi trường trong phát triển kinh tế xã hội: Nghiên cưu ở hai tỉnh Quảng Trị và Hà Giang.

7. Tô Thúy Nga (2015), Tích hợp nội dung bảo vệ môi trương và ứng phó với biến đổi khí hậu trong quy hoạch phát triển kinh tế - xã họi.

\section{INTEGRATION OF ENVIRONMENTAL PROTECTION REQUIRE- MENTS INTO SECTORAL LEGAL SYSTEMS IN VIETNAM - SOME THEORETICAL ISSUES Mai Thanh Dung ${ }^{1}$, Nguyen Minh Khoa ${ }^{1}$, Phan Thi Thu Huong ${ }^{1}$ \\ ${ }^{1}$ Institute of Strategy and Policy on natural resources and environment}

Abstract: Increasing concern about the environment and the goal of sustainable development are the driving forces that promote the integration of the environment in development policies, as well as concretization in integrating environmental protection requirements into sectoral legal systems. Integrating environmental protection requirements plays a huge role in ensuring the uniformity and harmonization of regulations on environmental protection, overcoming overlaps, conflicts and shortcomings in the legal system, thereby improving the enforcement of environmental protection in general. This is also an urgent need for Vietnam in the current legal context. Based on the analysis of relevant domestic and foreign studies to clarify the formulation and development of theories on integrating environmental protection requirements, the paper explains the need and identifies orientations on integrating environmental protection requirements into sectoral legal systems in Vietnam.

Keywords: Integrating environmental protection requirements, sectoral legal systems, sustainable development. 